\title{
Silencing the Self and Personality Vulnerabilities Associated with Depression
}

\author{
Avi Besser, Gordon L. Flett and Paul L. Hewitt
}

In this chapter, we examine how personality factors associated with depression relate with self-silencing, a contextual perspective that focuses on interpersonal factors, with the following two main goals. First, we present the argument that there are many reasons why people engage in self-silencing, and these reasons reflect personality vulnerability factors associated with depression that also happen to be associated with self-silencing. While Jack (1991, 1999a) argues that a person self-silences to maintain existing interpersonal relationships, we contend that self-silencing can be motivated by many goals and objectives. Second, we outline our current work on self-silencing and personality vulnerability factors associated with depression. We argue that self-silencing is not only associated with a tendency to be depressed but also with some core personality traits associated with depressive vulnerability. Moreover, we argue that selfsilencing combines with these personality factors, either as a mediating or a moderating factor, to increase the risk for elevated levels of psychological distress.

The three main personality factors we will focus on are dependency, selfcriticism, and perfectionism. The main motive for self-silencing among people with high levels of dependency and neediness is the desire to maintain relationships. However, self-evaluative concerns also play a significant role and contribute to self-silencing tendencies. People with high levels of self-criticism may silence the self because they are self-punitive and feel a sense of shame about aspects of their character and behavior. Similarly, perfectionistic people may self-silence because they are fearful of making mistakes and of the consequences of making mistakes. They may also engage in self-silencing because they are overly invested in publicly presenting an image of perfection. 
Although dependency, self-criticism, and perfectionism are distinguishable orientations, they have certain factors in common that should contribute to a shared tendency toward silencing the self. While it is recognized, generally, that dependent individuals will make extreme sacrifices to gain the love and approval of others, research indicates that self-criticism and perfectionism are also associated with concerns about losing the approval of other people (Hewitt \& Flett, 1991; Luthar \& Blatt, 1993). It is also possible for self-criticism and perfectionism to be evident in the interpersonal sphere-people may be self-critical because of inadequate behavior in social situations and people may be highly invested in meeting the perfectionistic expectations of other people and in trying to portray themselves in public as flawless (see Hewitt et al., 2003). It is our awareness of the interpersonal aspect of each of the constructs that has contributed to our interest in conducting a research program on the role of these personality factors in how new mothers adjust to the transition to parenthood and the associated relationship challenges and role demands. Clearly, all of the personality factors considered in this chapter have a clear interpersonal component.

In what follows, we describe each of the personality constructs mentioned previously in more detail, with a particular emphasis on how each is conceptualized and how each is relevant to an understanding of silencing the self. We summarize research conducted in our laboratories on personality and silencing the self and outline the implications of the associations between self-silencing and personality vulnerabilities. Finally, we conclude by discussing the negative emotional, interpersonal, and health consequences for people who self-silence and who are characterized by these personality vulnerability factors. In particular, we analyze the associations among self-silencing, personality vulnerabilities, and stress, and present the argument that people with vulnerable personalities who also engage in self-silencing may suffer from chronic and destructive forms of stress that may result, ultimately, in health problems.

\section{Dependency and Self-Criticism: The Anaclitic and Introjective Orientations}

Research on personality and depression has been a predominant theme in the personality literature (see Flett, Hewitt, Endler, \& Bagby, 1995). While earlier work focused extensively on attributional style and depression, more recent work has focused on constructs such as self-criticism, dependency, perfectionism, optimism-pessimism, and reassurance seeking. The dimensions of dependency and self-criticism were introduced and described at length by Blatt $(1974,2004)$. Dependency is a reflection of an anaclitic orientation that involves a preoccupation with other people and a need to keep them in close proximity. A high level of dependency is derived from an insecure attachment style (see 
Levy, Blatt, \& Shaver, 1998; Zuroff \& Fitzpatrick, 1995). In contrast, selfcriticism is a reflection of an introjective orientation that involves an evaluative focus on achieving personal goals and working toward standards in an autonomous fashion (see Blatt, Quinlan, Chevron, McDonald, \& Zuroff, 1982). However, the essence of this construct is a highly punitive, evaluative response to the self when standards are not achieved and expectations are not met. Blatt and Blass (1996) stated that the self-critical orientation reflects a need for selfdefinition and development of a sense of personal identity, while the dependent orientation reflects a need for relatedness and association with other people.

Blatt and colleagues defined a theory of personality involving the dimensions of dependency and self-criticism (Blatt, 1990; Blatt, Cornell, \& Eshkol, 1993; Blatt et al., 1982). This theory is consistent with the long tradition that contrasts other and self-directedness as two basic modalities of human experience. Blatt and colleagues suggested also that the adequate coordination between interpersonal relatedness and self-definition might reduce stress and lead to physical and psychological well-being (Blatt et al., 1993). According to this model, normal development is characterized by a dialectic interweaving of other and self-directedness, leading to a flexible balancing of the characteristic capacities involved in these two processes (Helgeson, 1994). These two processes evolve in an interactive, reciprocally balanced, dialectic process from birth through senescence (Blatt, 1974, 1990, 1995; Blatt \& Blass, 1996). This model assumes that individual differences in the relative emphasis on each of these processes delineate two personality styles-self-criticism and dependency-each with favored modes of cognition and coping strategies. An overemphasis on selfcritical or dependency motives results in dysfunctional attitudes and is assumed to constitute vulnerability to depression.

Extensive empirical research has found a strong positive association between self-criticism and depression and a less robust but still significant association between dependency and depression (Besser, 2004; Besser \& Priel, 2003a,b, 2005a,b; Besser, Priel, Flett, \& Wiznitzer, 2007; Nietzel \& Harris, 1990; Priel \& Besser, 1999, 2000), and this general pattern of findings has continued to emerge in recent years. However, two important caveats about the stronger association between self-criticism and depression need to be noted. First, the decidedly less robust association between dependency and depression is due, in part, to the fact that the dependency construct includes an adaptive component that reflects establishing a healthy connectedness to other people. That is, dependency appears to include both vulnerability and resilience components (Blatt, Zohar, Quinlan, Zuroff, \& Mongrain, 1995; Rude \& Burnham, 1995). It is the vulnerability component of dependency that should be most relevant to silencing the self. Second, recent data suggest that self-criticism and dependency interact so that people characterized jointly by these two orientations are particularly at risk for depression (see Mongrain \& Leather, 2006). 
Silencing the self is believed to be especially likely to occur in relationship contexts (see Jack, 1999a). It is important to note that an extensive and growing body of research also highlights the relevance of both self-criticism and dependency in relationship outcomes and relationship processes (for a review, see Blatt, 2004). This research suggests that both dependency and self-criticism undermine relationship satisfaction, but for very different reasons (e.g., Whiffen \& Aube, 1999). While the excessive need for reassurance of people high in dependency may alienate their partners, self-critical people have a hostile interpersonal style that leads others to reject them (Mongrain, Lubbers, \& Struthers, 2004). The main point for our purposes is that selfsilencing, dependency, and self-criticism are all relevant to behaviors, events, and processes that occur in relationships, and this points to the possibility that these constructs may be interrelated.

\section{Silencing the Self, Dependency, and Self-Criticism}

Given this description, what is the link between silencing the self and both dependency and self-criticism? And why should there be an association? If viewed from a conceptual perspective, the case for linking self-silencing and dependency seems rather obvious. Indeed, in a previous paper, Whiffen and Aube (1999) discussed self-silencing within the context of dependency and neediness and postulated that women high in dependency and interpersonal neediness are likely to engage in self-silencing behavior in order to further their relationship goals. Whiffen (2007) has gone on to suggest that many women suffer from "a secret sadness" that is rooted deeply in maladaptive relationship patterns. The notion of a "secret sadness" follows from Blatt and Zuroff's (1992) statement that "dependent individuals rely intensely on others to provide and maintain a sense of well-being, and therefore have great difficulty expressing anger for fear of losing the need gratification that others can provide" (p. 528). The unwillingness or inability to express anger is a central characteristic of women who engage in selfsilencing (see Jack, 2001).

But why should self-criticism be linked with self-silencing? People high in selfsilencing have been described as hearing self-condemning, harsh voices in their heads (e.g., Jack, 1999a), almost as if they have internalized unrealistic societal values that are being used as a guide for self-evaluation. Intuitively, it seems natural that people who are unsure of themselves and feel negatively toward themselves would keep their deficiencies, concerns, and true feelings to themselves, especially if they have unfulfilled desires for social approval and recognition for positive accomplishments and clear successes. We would also suggest that one reason why self-criticism and self-silencing are associated is that there is a reciprocal association between these variables. Initially, self-critical people will silence themselves, but this act of self-negation, in turn, should foster additional 
feelings of self-reproach and reductions in self-esteem, and this gets reflected in an increasingly negative personal identity.

Existing evidence points to a link between self-criticism and self-silencing. For instance, Jack (1999a) provided descriptive case examples of self-critical individuals who engage in self-silencing behavior. A possible link between self-criticism and self-silencing is also indicated by research showing that self-critical individuals are characterized by low levels of frankness and that they tend to avoid selfdisclosure (Wiseman, 1997). Self-critical people tend to pursue self-presentational goals that revolve around making a positive impression on other people and concerns about portraying certain emotional states (see Mongrain \& Zuroff, 1995). Finally, both self-criticism and dependency have been associated with an ambivalence regarding emotional expression (Mongrain \& Zuroff, 1994); perhaps this ambivalence is a by-product of the self-silencing process.

Initial data on this topic were reported by Besser, Flett, and Davis (2003). We examined the associations among self-criticism, dependency, self-silencing, loneliness, and depression in a sample of 167 university students, including a significant subset of participants who were currently in dating relationships. Dependency and self-criticism were assessed with the Depressive Experiences Questionnaire (DEQ; Blatt, D'Afflitti, \& Quinlan, 1976). We found that individuals with high levels of dependency tended to be characterized by silencing the self and this finding held regardless of whether the individuals were or were not in a current relationship, and regardless of levels of depressive symptoms as measured by the Center for Epidemiological Studies Depression Scale (CES-D; Radloff, 1977). Our analyses involving self-criticism provided evidence consistent with case descriptions of self-silencing people characterized by excessive self-criticism (see Jack, 1999a). Higher levels of self-criticism were associated with self-silencing regardless of relationship status. These data signify that many people with elevated self-criticism are characterized by high sensitivity to external feedback and may be aware of conflicting aspects of the public self versus the private self, so one protective approach they adopt is to engage in selfsilencing behavior in an attempt to maintain or improve their relationships. However, as noted, self-silencing is also evident among self-critical individuals who are not even in a current relationship. In general, these data are consistent with the results of a daily monitoring study that showed that self-critical individuals make fewer requests for social support and have a general style that distances them from other people (see Mongrain, 1998).

New research in our laboratories continues to explore the association between self-silencing and both dependency and self-criticism. As can be seen in Table 13.1, the initial results of a new study conducted on 227 university students from York University are very much in keeping with our previous results (Flett, Besser, \& Hewitt, 2009).

Overall levels of silencing the self were associated with both self-criticism $(r=.49)$ and dependency $(r=.37)$. Self-criticism was associated significantly 
Table 13.1 Correlations between Self-Silencing and Personality Measures

\begin{tabular}{lccccc}
\hline & & \multicolumn{4}{c}{ Self-Silencing Measures } \\
\cline { 3 - 6 } Measures & Total & External & Care & Self-Silence & Divided Self \\
\hline Self-criticism & .49 & .58 & .29 & .33 & .48 \\
Dependency & .37 & .46 & .47 & .21 & .14 \\
Self-oriented perf & .01 & .09 & .01 & -.02 & .04 \\
Other-oriented perf & -.01 & .05 & -.11 & -.08 & .12 \\
Socially prescribed perf & .27 & .29 & .10 & .21 & .31 \\
Perfectionism cognitions & .40 & .49 & .32 & .22 & .34 \\
PSP-promotion & .26 & .31 & .10 & .19 & .24 \\
PSP-avoid imperfect & .28 & .35 & .22 & .20 & .19 \\
PSP-avoid disclosing & .31 & .26 & .11 & .28 & .34 \\
High standards & .09 & .13 & .02 & .04 & .09 \\
Concern over mistakes & .36 & .39 & .23 & .26 & .30 \\
Doubts about actions & .33 & .38 & .22 & 2.5 & .28 \\
Parental expectations & .14 & .07 & .09 & .12 & .13 \\
Parental criticism & .23 & .21 & .12 & .21 & .26 \\
Shame & .38 & .45 & .22 & .30 & .32 \\
Neg social interactions & .35 & .33 & .25 & .34 & .37 \\
Daily hassles & .45 & .44 & .41 & .30 & .34 \\
Depression & .45 & .41 & .30 & .34 & .47 \\
\hline
\end{tabular}

Note: $p<.01$ when $r$ is .18 or greater. Based on $n=227$ students ( 157 women, 70 men). The following abbreviations were used: self-oriented perf (self-oriented perfectionism); other-oriented perf (other-oriented perfectionism); socially prescribed perf (socially prescribed perfectionism); PSP-promotion (perfectionistic selfpromotion); PSP-avoid imperfect (the need to avoid appearing imperfect); PSP-avoid disclosing (the need to avoid disclosing imperfections); and neg social interactions (negative social interactions).

with all four Silencing the Self Scale (STSS; Jack \& Dill, 1991) subscales, with the strongest association being between self-criticism and an externalized view of the self. The four subscales are Externalized Self-Perception, Care as Self-Sacrifice, Silencing the Self, and Divided Self (i.e., the public self does not reflect the true self). Dependency was correlated significantly with three of the four STSS subscales; the only subscale not associated with dependency was Divided Self.

Given the link between self-silencing and self-criticism, it is not surprising that self-silencing and self-blame are related. Ali and colleagues (2000) found a very strong association between self-silencing and self-blame among women with irritable bowel syndrome. A history of emotional abuse during adulthood was also associated with self-silencing and self-blame. This scale included items assessing various forms of emotional maltreatment, including being denigrated, insulted, and humiliated.

In our new study of self-criticism and dependency, we also included a selfreport measure of shame, in line with Jack's (1999a) observations about the relevance of shame in self-silencing. Specifically, we administered the Experience of Shame Scale (ESS) by Andrews, Qian, and Valentine (2002). This 25-item 
measure assesses characterological shame, behavioral shame, and bodily shame. Shame and self-criticism both involve negative self-evaluation, but shame involves a sweeping judgment of the total self (i.e., a global attribution) along with the sense that others are aware of this shamefulness. Shame is also similar to factors and processes presumed to underscore self-silencing because people who experience shame are cognizant of self-discrepancies and feel they are not meeting ideal standards (Tangney, Niedenthal, Covert, \& Barlow, 1998), as we discuss in greater detail later. Jack (1999a) noted that self-silencing stems, in part, from comparing the self to harsh, idealistic standards.

Our current results involving shame and self-silencing are also displayed in Table 13.1. As might be expected, ESS scores were associated with total selfsilencing and with scores on all four STSS subscales. Andrews and colleagues (2002) found that shame predicted susceptibility to depression in a longitudinal investigation, so it follows that individuals who self-silence and are characterized by shame are also at risk for substantial and persistent distress.

Comparative analyses suggest that shame and self-criticism have comparable associations with indices of distress, and that shame, self-criticism, and dependency are intercorrelated (see Flett et al., 2009). However, the results of a regression analysis predicting overall self-silencing scores indicate that these measures are not redundant with each other. Significant unique variance in self-silencing is predicted by shame, self-criticism, and dependency, and we regard this as evidence of the unique aspects of the link between shame and self-silencing.

We now turn to a description of perfectionism and its association with selfsilencing. Perfectionism is a construct that has been linked with self-criticism, both conceptually and empirically (see Blatt, 1995). Given the link between selfcriticism and self-silencing, it follows that perfectionism may also be associated with self-silencing. This possibility is explored in the next segment of this chapter.

\section{Perfectionism: A Multidimensional Construct}

A focus on the attainment of high standards is a continuing theme in research on personality and depression. Extensive research has explored the role of individual differences in perfectionism (Cox \& Enns, 2003; Hewitt \& Flett, 1991). This research indicates that certain dimensions of perfectionism may be associated not only with concurrent depressive symptoms but also with the chronicity and persistence of depressive symptoms (Cox \& Enns, 2003; Hewitt, Flett, Ediger, Norton, \& Flynn, 1998). Research with the Multidimensional Perfectionism Scale (MPS; Hewitt \& Flett, 1991) has focused on three dimensions: self-oriented perfectionism (i.e., exceedingly high personal standards), other-oriented perfectionism (i.e., demanding perfection from others), and socially prescribed 
perfectionism (i.e., a pressure to be perfect imposed on the self). Socially prescribed perfectionism has shown a consistent association with depression (see Flett \& Hewitt, 2002; Flett, Besser, \& Hewitt, 2005).

Another highly relevant perspective for understanding depression involves individual differences in self-silencing. The construct of self-silencing was hypothesized by Jack (1991) to account for the preponderance of depression among women. However, subsequent research has shown that self-silencing is relevant for both women and men (Thompson, 1995). People high in selfsilencing are self-sacrificing individuals who keep their distress to themselves in an attempt to maintain or improve interpersonal relationships. Their distress often takes the form of unexpressed anger (see Jack, 1999a, 2001). People high in self-silencing conceal their true feelings out of desires to maintain relationships and obtain the approval of significant others.

A link between perfectionism and self-silencing follows from Jack's (1999a) observation that the standards used for self-evaluation are central to an understanding of self-silencing behavior. Jack suggested that a sense of inferiority and self-reproach stems from the idealistic standards that the self-silencer uses to judge the self. The standards themselves have a social aspect because they reflect social dictates and a sense of being obliged to act in a socially approved of manner and to achieve prescribed goals. Unfortunately, for self-silencing individuals, this focus on ideals and being perfect as the accepted standard should make them susceptible to dysphoria when they perceive a substantial gap between the actual self and the goal of being perfect.

Jack (1999a) provided a series of compelling case examples of distressed people who clearly exhibited perfectionistic characteristics and who engaged in self-silencing. These people appear to suffer from the "tyranny of the shoulds" described by Horney (1950) and by Ellis (2002), and they seem to be characterized jointly by elements of both socially prescribed perfectionism and selforiented perfectionism. For instance, a physician named Carol described the perfectionistic pressures inherent in the "Supermom syndrome." Specifically, she noted that:

You can't be Supermom and can't do it all, and yet we all have this image that we can, and we measure ourselves by the standards of our mothers in terms of raising kids. You know, I feel guilty when I'm not there with the warm milk and cookies and when I'm not putting every Band-Aid on. And then I'm guilty because I'm not enough of a spouse for my husband, and I'm guilty because I'm not doing an adequate job professionally and never quite getting it right. (Jack, 1999a, p. 233)

Carol responded to these pressures by presenting as a picture of a person who apparently acquiesced to these demands while silencing the self.

Jack (1999a) also reported the case of a male physician named Dan. This doctor revealed his tendency toward self-silencing by engaging in workaholic and perfectionistic tendencies that were in accordance with social obligations 
and expectations. He was described as suffering from a litany of shoulds that were rooted, in part, in an externalized self-perception and "acquiescence to unrealistic standards" (p. 239).

Our analysis of the various perfectionism dimensions indicates that selfsilencing is particularly relevant to socially prescribed perfectionism, given the tendency for socially prescribed perfectionists to need approval and to strive to please others (Hewitt \& Flett, 1991, 2004). These people feel that perfectionistic demands have been imposed on them. This sense of being treated unfairly should foster a sense of resentment that is akin to the anger of self-silencing women described by Jack (2001). Also, socially prescribed perfectionism is associated with passive, indirect responses to life problems in a manner that is reminiscent of self-silencing (Hewitt \& Flett, 2002). A link between socially prescribed perfectionism and self-silencing can be inferred from results of a study of dating students (see Flett, Hewitt, Shapiro, \& Rayman, 2003). This study showed that socially prescribed perfectionism was associated with low scores on a measure of "voice." Voicing one's concerns is one way of responding to dissatisfaction in interpersonal relationships.

\section{Research on Silencing the Self and Perfectionism}

The initial study of perfectionism and self-silencing was conducted by Geller, Cockell, Hewitt, Goldner, and Flett (2000). They administered the MPS and the STSS to 21 anorexic patients, 21 women with other psychiatric disorders, and 21 normal control participants. Geller and colleagues (2000) examined the correlations for the total sample by collapsing across the groups. These analyses showed that both self-oriented and socially prescribed perfectionism were associated robustly with all STSS measures ( $r$ 's ranging from .55 to .77). However, there is a need to re-examine the magnitude of the associations between silencing the self and trait perfectionism in another sample given that the extreme scores among the group of anorexic patients likely inflated the magnitude of these correlations.

The associations among perfectionism and silencing the self in college students were explored by Flett, Besser, Hewitt, and Davis (2007). A sample of 202 university students completed the MPS (Hewitt \& Flett, 1991, 2004), the STSS, and Radloff's (1977) CES-D Scale. The results showed that self-oriented perfectionism was not associated significantly with overall scale scores, but there was a significant association between self-oriented perfectionism and the Silencing the Self subscale. The main finding that emerged was that socially prescribed perfectionism was associated significantly with the overall scale score $(r=.32)$ and with all four STSS subscales, with correlations ranging from .19 to .42. Additional analyses tested the possibility that self-silencing may mediate or moderate the association between socially prescribed perfectionism and depression. Indeed, we found that depression was elevated among socially prescribed 
perfectionists who were also high in self-silencing. These data are described in more detail in a subsequent segment of this chapter.

Recently, we have re-examined the association between perfectionism and silencing the self as part of the study mentioned earlier that also included indices of dependency and self-criticism. This newer investigation is unique in that it examined perfectionism and silencing the self from a more comprehensive perspective. Specifically, this study included four different measures of perfectionism: (1) Hewitt and Flett's (1991) MPS; (2) the MPS (Frost, Marten, Lahart, \& Rosenblate, 1990); (3) the Perfectionism Cognitions Inventory (PCI; Flett, Hewitt, Blankstein, \& Gray, 1998); and (4) the Perfectionistic Self-Presentation Scale (Hewitt et al., 2003). We will focus initially on the results involving trait levels of self-oriented, other-oriented, and socially prescribed perfectionism. The pattern of correlations obtained in this study was very much in keeping with the findings obtained by Flett and colleagues (2007). As can be seen in Table 13.1, self-oriented and other-oriented perfectionism were not associated significantly with silencing the self. However, socially prescribed perfectionism had a modest but significant association with overall scale scores. It was also associated with three of the four STSS subscales with the strongest associations being with subscales assessing Externalized Self-Perception and Divided Self.

While these data are interesting and certainly fit with our conceptualization of how trait perfectionism and silencing the self should be associated, many of the findings obtained with the other perfectionism dimensions included in this study were more robust in a statistical sense, and they seem particularly meaningful from a theoretical perspective. First, consider the results obtained with the Frost MPS (see Table 13.1). Frost and colleagues (1990) developed a multifactor measure that assesses aspects of perfectionism directed toward the self (high personal standards, doubts about actions, and concern over mistakes) and two aspects of perfectionism that reflect the perceived presence of parental demands on the self (i.e., high parental expectations and parental criticism). Historically, research has established that concern over mistakes and doubts about actions are the two dimensions linked most consistently with psychological distress, and experimental work has focused on the negative reactions of people high in concern over mistakes once a mistake has been made (for a review, see Frost $\&$ DiBartolo, 2002).

As can be seen in Table 13.1, both concern over mistakes and doubts about actions were associated significantly with silencing the self. A smaller but still significant association was also found between silencing the self and high parental criticism. The link with concern over mistakes suggests that for some people, their self-silencing is motivated by the desire to avoid making mistakes and the consequences of these mistakes. The nature of these consequences can vary substantially as a function of the individual's interpersonal context. If we were assessing the battered women who were included in the research described originally by Jack and Dill (1992), these women were exceptionally high in 
silencing the self. Undoubtedly their focus would be on fears about making a mistake (or being perceived as making a mistake) that would then provide a misguided, self-serving rationale for their abusive partner to engage in further mistreatment. However, the current findings were derived from a sample of university students. A significant proportion of these students indicated that they have experienced maltreatment during childhood, and this accounts, in part, for the obtained association. However, other students have not been maltreated and the link between silencing the self and concern over mistakes simply reflects fears of failure and their great sensitivity to failure feedback and the self-esteem implications of being imperfect.

Past theory and research have focused on self-silencing in the romantic relationship context. A study by Thompson, Whiffen, and Aube (2001) found that self-silencing was associated with perceiving the partner as critical and intolerant, and both of these factors were associated with greater depression. In this context, they posited that self-silencing is a form of interpersonal coping. However, our results with the Frost MPS showed that other forms of criticism such as perceived parental criticism are also linked with self-silencing. One important direction for future research is to examine self-silencing in children and adolescents. Clearly, children and adolescents who desire parental approval but resent perfectionistic pressures being put on them are in a cognitive and emotional bind that is akin to the conflict described by Horney (1950): When children are not able to express their anger toward parental figures, it becomes repressed and creates basic hostility and basic anxiety. The hostility must remain repressed and perhaps gets directed inward at the self.

\section{Self-Silencing and Perfectionistic Automatic Thoughts}

Table 13.1 also includes information about the association between self-silencing and perfectionism cognitions. It is important to assess perfectionism cognitions and self- statements because there have been extensive writings on the internal dialogues of self-silencing individuals and how the internal dialogue fails to be expressed (Jack, 1999a,b, 2001). The PCI (Flett et al., 1998) is an attempt to assess automatic thoughts about the need to be perfect and cognitive rumination over mistakes and imperfections that characterize perfectionists who can't help thinking about mistakes. The PCI is based on the premise that perfectionists who sense a discrepancy between their actual self and the ideal self or their actual level of goal attainment and high ideals will tend to experience automatic thoughts that reflect perfectionistic themes (Besser, Flett, \& Hewitt, 2004; see Flett et al., 1998). It is believed that perfectionists with high levels of perfectionism cognitions are especially susceptible to negative affect in the form of depression about failure to attain perfection in the past, as well as in the form of anxiety about the likelihood of failing to attain perfection in the future. 
The PCI has a range of item content that reflects the frequency of direct thoughts about the need to be perfect, as well as thoughts of an individual's cognitive awareness of his or her imperfections. Several thoughts on the PCI such as "I should be perfect," "I should never make the same mistake twice," and "I must be efficient at all times" are very much in keeping with general observations by Albert Ellis (2002) about perfectionism and irrational thinking. Much of the automatic thought content comes in the forms of "shoulds" and "oughts" that reflect a pressure to live up to real or imagined expectations.

As can be seen in Table 13.1, the PCI was correlated with overall silencing the self scores $(r=.40)$, and it was also associated with all four subscales. Secondary analyses of these data suggest that PCI predicts unique variance in self-silencing in hierarchical regression analyses, over and above the variance attributable to trait perfectionism (Nepon, Flett, Besser, \& Hewitt, 2009). Thus, the internal dialogue of some self-silencing individuals is focused on the need to be perfect and an awareness of not measuring up to extreme perfectionistic ideals. As noted by Ellis (2002), the ultimate question here is why has perfectionism attained such an irrational importance to the extent that the quest for perfection can dominate cognitive processes and be ruminated about over and over? While the family may play a significant role in the development of perfectionism, we must also acknowledge cultural pressures and messages that emphasize the need to be perfect in general and to be perfect in specific life domains (e.g., perfect physical appearance) in order to be regarded as a worthwhile individual who is desired by other people.

\section{Silencing the Self and Perfectionistic Self-Presentation}

Horney (1950) stated that when it comes to emotional displays, neurotic perfectionists tend to display friendliness toward others because there is a palpable sense that they should be friendly out of a prescribed need to be obedient and devoted to others. This observation by Horney predated the more recent discovery of a facet of the perfectionism construct known as perfectionistic selfpresentation; it is this facet that seems most relevant to silencing the self. Perfectionistic self-presentation is based on the premise that certain perfectionists are highly invested in covering up their mistakes and are preoccupied with trying to present themselves as perfect (i.e., self-promotion) or defensively minimizing the number of mistakes that are on display for others to see.

A need to present a perfect self is implicated in the accounts that were obtained by Stephens (1987) as part of her investigation of 50 adult female suicide attempters. Consider the following excerpt:

My mother wanted me to be perfect, strong, able to take care of any kind of problem that came forth. It was a burden to me because I couldn't show her how truly things bothered me. I had to be this super daughter that never got upset and never cracked or anything and it was a really hard thing. She put out, 'Oh, my 
daughter's never given me any trouble. She's a perfect daughter; she's always been a perfect daughter.' I didn't want to be perfect. I wasn't strong; I was crumbling inside. I wasn't perfect. (Stephens, 1987, p. 114)

This excerpt highlights the fact that socially prescribed perfectionism and the need to appear perfect can be linked inextricably for many people. In this particular instance, the need to present a façade stemmed from maternal expectations.

Hewitt and colleagues (2003) hypothesized that there are stable individual differences in the tendency to engage in perfectionistic self-presentation and that there are three components to perfectionistic self-presentation. The Perfectionistic Self-Presentation Scale (PSPS, Hewitt et al., 2003) was developed to assess three aspects of perfectionistic self-presentation-namely, perfectionistic self-promotion, an unwillingness to display imperfections, and an unwillingness to disclose imperfections to others. This third dimension involves avoidance of personal communications about issues that could reveal the perfectionist's flaws.

Initial research indicates that perfectionistic self-presentation is indeed a multidimensional construct (Hewitt et al., 2003). Although perfectionistic selfpresentation is correlated significantly with trait perfectionism, a perfectionistic self-presentational style still predicts unique variance in psychological distress after taking into account the variance attributable to perfectionism as assessed by the respective Multidimensional Perfectionism Scales. Other research with the PSPS indicates that perfectionistic self-presentation is associated with low levels of appearance self-esteem (Hewitt, Flett, \& Ediger, 1995) and relationship difficulties in married couples (Flett, Hewitt, Shapiro, \& Rayman, 2003; Habke, Hewitt, \& Flett, 1999). Elevations in perfectionistic self-presentation are also correlated with facets of the anxiety sensitivity construct, including a fear of expressing publicly observable symptoms of anxiety (Flett, Greene, \& Hewitt, 2004).

There is little doubt that self-silencing individuals engage in perfectionistic self-presentation. Jack (1999a), in fact, suggested that while women may look passive and compliant, it actually takes a great deal of effort to consciously selfmonitor and inhibit the self in order to project this image. It is even more difficult when the image being presented is one that emphasizes flawlessness.

Accumulating evidence is in keeping with the proposed association between self-silencing and perfectionistic self-presentation. Indeed, Geller and colleagues (2000) found evidence of a robust link between perfectionistic self-presentation and silencing the self, but we felt that the select nature of their clinical sample pointed to a need to re-examine this issue. Accordingly, the PSPS was included in our new study conducted with university students (see Nepon et al., 2009). The results are shown in Table 13.1. Note that all three PSPS facets were associated with the STSS Silencing the Self subscale, with the strongest association being between self-silencing and the need to avoid disclosing imperfections to others. 
This association has particular implications in therapy and counseling contexts because it is unlikely that perfectionistic self-silencers would be willing to reveal their true concerns and past mistakes and shortcomings, if they even sought help in the first place. The help-seeking process can be regarded as a process that involves threats to self-esteem because inadequacies and imperfections will have to be revealed to others (for a related discussion, see Hewitt \& Flett, 2007).

Our most recent work has been focused more extensively on this link between self-silencing and perfectionistic self-presentation. The purpose of these investigations was to not only extend our findings but also examine the generalizability of the obtained associations because the data described thus far were obtained entirely from Canadian university students. Our recent work conducted in Israel attests to the generalizability of these findings, briefly outlined next.

A recent experimental study was conducted to examine the extent to which individual differences are associated with upset after experiencing a public humiliation (Besser, Flett, \& Hewitt, 2009b). Our interest in humiliation stems not only because of its potential relevance to self-presentational concerns and self-silencing but also from evidence indicating that humiliation is a potent interpersonal stressor that elicits profound depressive reactions (see Brown, Harris, \& Hepworth, 1995; Farmer \& McGuffin, 2003). It was our expectation that perfectionistic self-presenters high in self-silencing would be especially distressed in such a situation. A sample of 150 students in Israel completed a battery of personality measures and reported their affective reactions to a hypothetical scenario (i.e., learning while with other people that the news has been made public that one's partner has been unfaithful). This focus on hypothetical scenarios is in keeping with eliciting feelings of shame and guilt by having people respond to hypothetical scenarios listed on measures such as the Test of Self-Conscious Affect (Tangney, Wagner, \& Gramzow, 1989), which assesses emotions such as shame and guilt. Analyses of our data have confirmed that perfectionistic self-presenters, relative to those low in perfectionistic self-presentation, do indeed report stronger distress reactions. Self-silencing was not associated with stronger distress reactions. However, in keeping with the investigation by Flett and colleagues (2007), strong associations were found between self-silencing and perfectionistic self-presentation. This pattern of findings suggests that those people who are prone to distress following humiliation will be likely to "suffer in silence" and not express their distress to others.

Another new study with data collected in Israel examines perfectionism, self-silencing, depression, and marital adjustment in married couples (Besser, Flett, \& Hewitt, 2009a). Both perfectionism and self-silencing have been implicated separately in prior research on poor functioning in relationships (see Haring, Hewitt, \& Flett, 2003; Harper \& Welsh, 2007). A unique aspect of this new study conducted with 72 couples is that each participant provided self-reports of self-silencing and depression and they also rated their partner's degree of self-silencing and depression. Initial analyses have confirmed that 
Table 13.2 Correlations between Self-Silencing and Perfectionistic Self-Presentation

\begin{tabular}{lccccc}
\hline & & \multicolumn{4}{c}{ Self-Silencing Measures } \\
\cline { 3 - 5 } Measures & Total & External & Care & Self-Silence & Divided Self \\
\hline PSP-promotion & $.25^{* * * *}$ & $.25^{* *}$ & .08 & $.21^{* * *}$ & $.24^{* * *}$ \\
PSP-avoid imperfect & $.34^{* * * *}$ & $.38^{* *}$ & .13 & $.28^{* * *}$ & $.25^{* * * *}$ \\
PSP-avoid disclosing & $.37^{* *}$ & $.27^{*}$ & .13 & $.36^{* *}$ & $.33^{* *}$ \\
\hline
\end{tabular}

Note: " $p<.05 ; " * p<.01$. Based on $n=144$ respondents. The following abbreviations were used: PSPpromotion (perfectionistic self-promotion); PSP-avoid imperfect (the need to avoid appearing imperfect); and PSP-avoid disclosing (the need to avoid disclosing imperfections).

both perfectionistic self-presentation and self-silencing associated significantly with self-reported depression and reduced marital satisfaction. In addition, as can be seen in Table 13.2, perfectionistic self-presentation and self-silencing are correlated significantly. The magnitude of the correlations across the four STSS factors is quite comparable to the magnitude of correlations reported in Table 13.1.

\section{Personality Vulnerabilities and Depression: Self-Silencing as a Moderator or Mediator}

In a previous review paper, Flett and colleagues (1995) issued a call for research that tests the extent to which established risk factors combine within an individual such that the confluence of factors is linked with elevated levels of distress. It follows logically that someone who is characterized by high levels of selfcriticism, dependency, and perfectionism should tend to have greater distress than the person who has high self-criticism but not elevated levels of the other two personality factors. By the same token, it follows that people characterized jointly by personality vulnerabilities and a relatively high level of self-silencing will experience greater levels of dysphoria (i.e., the moderational hypothesis). A moderator is present when one variable (i.e., an independent variable) is moderated or influenced by the level of another variable (i.e., the moderator); these variables combine and interact to have a joint influence on the level of another variable. ${ }^{1}$

It is just as possible that one of the ways that personality vulnerabilities translate into elevated levels of dysphoria is through the already established association that these personality vulnerability factors have with silencing the self (i.e., the mediational hypothesis). A mediator is when an association exists between two other variables because of their mutual link with an intervening variable, which is known as the mediator. 
We have evaluated both of these possibilities in our initial investigations in this area. Specifically, the Flett and colleagues' (2007) study with self-silencing and the Hewitt and Flett MPS also evaluated whether the association between perfectionism and depression is moderated or mediated by self-silencing. In particular, we tested whether socially prescribed perfectionism interacts with elevated self-silencing to produce elevated levels of depression and the related possibility that self-silencing mediates the link between socially prescribed perfectionism and depression. We observed that at the conceptual level, the "silencing the self" construct has several components and features that are relevant to socially prescribed perfectionism and that ought to combine with socially prescribed perfectionism to produce elevated depression. In general, self-silencing is believed to contribute to a "loss of self" that is linked with depression (see Drew, Heesacker, Frost, \& Oelke, 2004), and this loss of self should be particularly deleterious for socially prescribed perfectionists who feel hopeless to achieve the standards imposed on them. Also, certain aspects of the silencing the self construct should be particularly damaging for socially prescribed perfectionists. Most notably, individuals with a high socially prescribed perfectionism who also tend to judge themselves by external standards should be at risk because the impact of their inability to meet expectations is magnified.

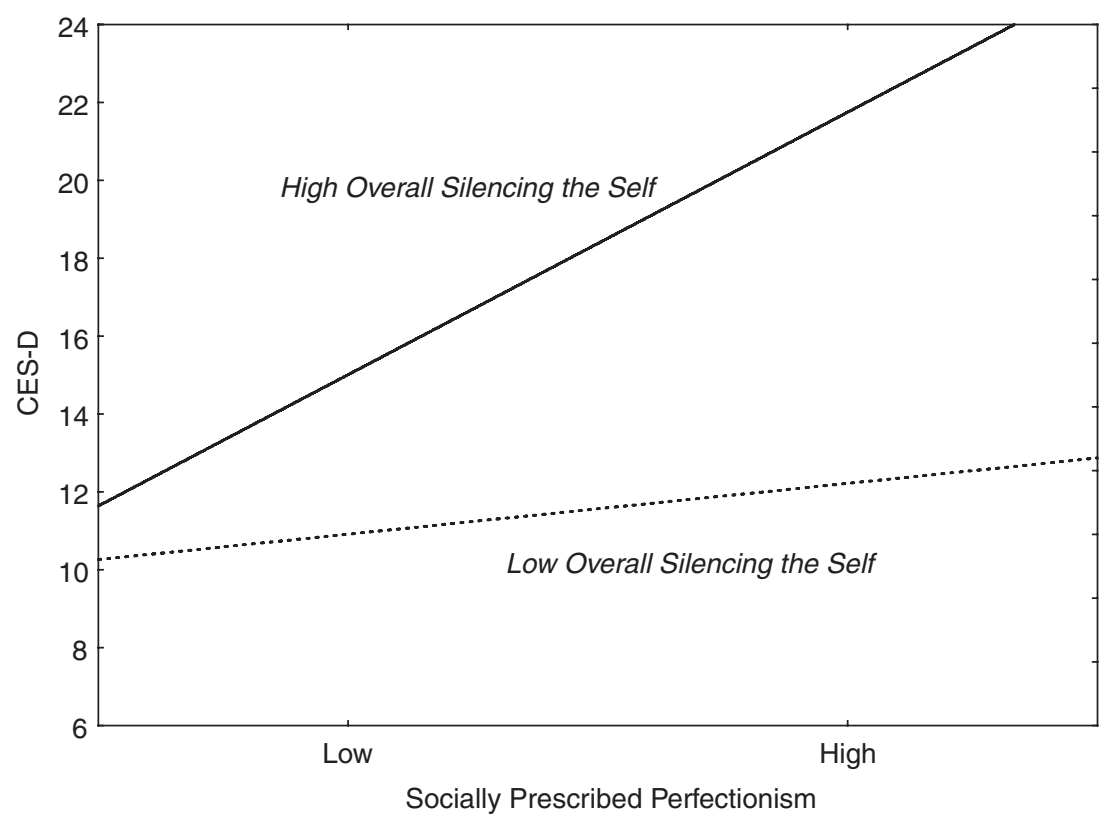

Figure 13.1 The relations between high $(+S D)$ and low $(-S D)$ levels of socially prescribed perfectionism and depressive symptoms for high $(+S D)$ and low $(-S D)$ levels of overall Silencing the Self. 
The main findings of interest that emerged from our statistical tests of the hypothesized moderational effect(s) are summarized in Figure 13.1 and Figure 13.2.

It was found that overall self-silencing did indeed interact with socially prescribed perfectionism to predict increased distress. Further analyses of selfsilencing in terms of the individual STSS subscales found that it was the Externalized Self-Perception factor that combined with socially prescribed perfectionism to produce elevated levels of depressive symptoms. This follows in that a tendency to judge the self by external standards should magnify the salience and impact of socially prescribed perfectionism on personal functioning.

Other tests supported the mediation hypothesis. The notion that self-silencing is a mediator of the link between socially prescribed perfectionism and depression is in keeping with coping models that suggest that a maladaptive response to stressful circumstances mediates or moderates the link between perfectionism and depression (Flett, Besser, \& Hewitt, 2005; see Hewitt \& Flett, 2002). In the present instance, the tendency for socially prescribed perfectionists to be high in self-silencing would constitute an ineffective way of responding to interpersonal conflict and stress, and this tendency to silence the self could, in turn, contribute

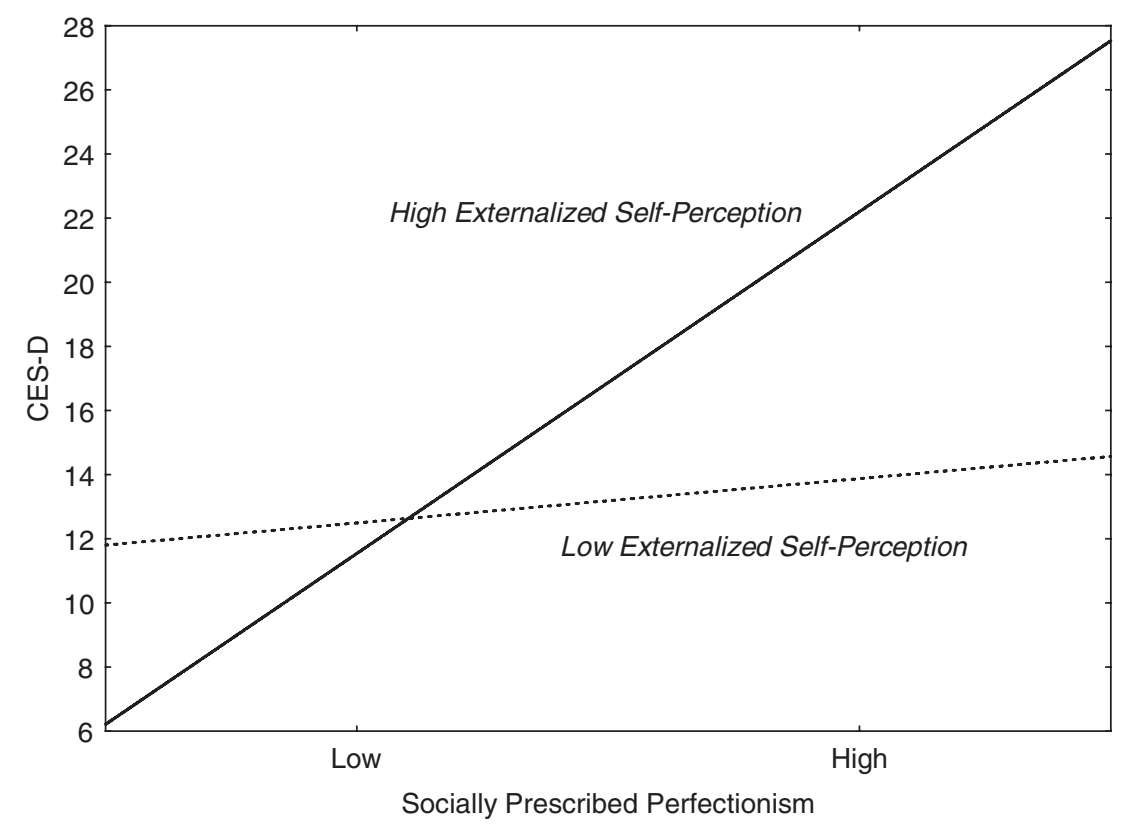

Figure 13.2 The relations between high $(+S D)$ and low $(-S D)$ levels of socially prescribed perfectionism and depressive symptoms for high $(+S D)$ and low $(-S D)$ levels of Externalized Self-Perception subscale. 


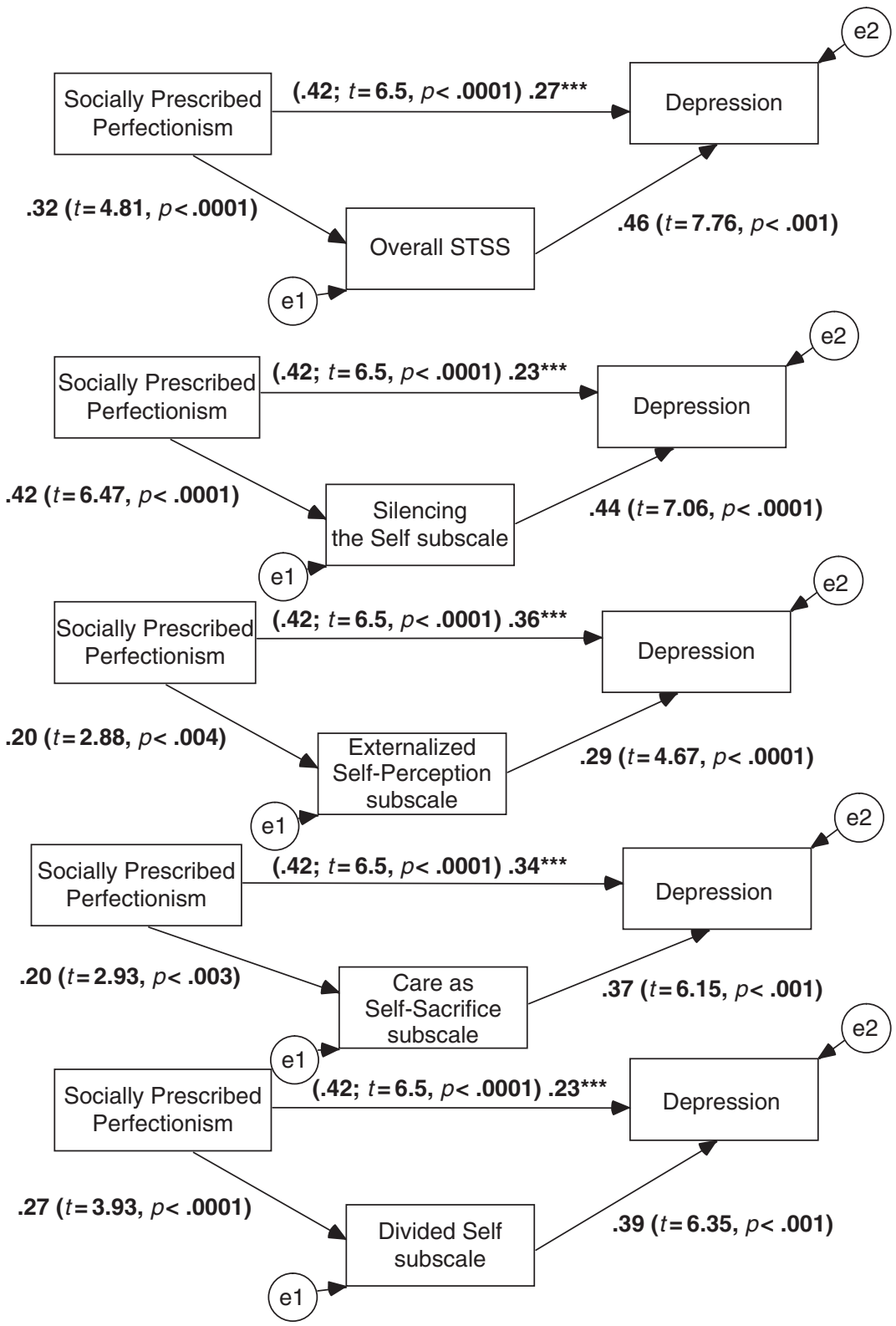

Figure 13.3 Direct and indirect associations between socially prescribed perfectionism and depression and the mediating role of STSS and STSS subscales.

Note: Bolded estimates are significant regression coefficient $\beta$ s. Numbers in parentheses are $\beta$ s before STSS scores were entered into the model. Small circles represent residual variances, and unidirectional arrows depict hypothesized associations. 
to depression. A mediational model is also suggested to the extent that selfsilencing does indeed involve a loss of sense of self and a negative self-view, which, in turn, should be related to depression.

What did the mediational tests reveal? The results of these analyses are summarized in Figure 13.3. First, the mediational analyses showed that all facets of the self-silencing construct partially but significantly mediated the link between socially prescribed perfectionism and depression. Thus, some of the dysphoria reported by socially prescribed perfectionists is due to the tendency for socially prescribed perfectionism to be associated with various aspects of self-silencing.

Collectively, these data highlight the need to consider the interplay between self-silencing and personality vulnerability factors when predicting levels of psychological stress. As indicated by Hewitt and Flett (2002), perfectionists can respond with maladaptive coping responses or adaptive coping responses when confronted with stressful, challenging circumstances. Self-silencing in this situation can be a form of avoidance that may seem adaptive but actually perpetuates elevated psychological distress. Clearly, this possibility merits further investigation in longitudinal research.

In addition, research should consider other factors of potential importance that are common to the various personality vulnerability factors. One important direction is to incorporate individual differences in rumination; parenthetically, both rumination and self-silencing were suggested as factors that contribute to the gender difference in depression. Rumination has been linked empirically with self-criticism, dependency, and perfectionism (for a review, see NolenHoeksema, Wisco, \& Lybubomirsky, 2008). Rumination is also associated with shame (Orth, Berking, \& Burkhardt, 2006), and has also been linked with silencing the self (Hart \& Thompson, 1996). The tendency to brood should keep current and previous inadequacies, mistakes, and humiliations active cognitively and highly salient for the distress-prone individual, and this should contribute to prolonged depression while the vulnerable individual continues to engage in self-silencing.

\section{Personality Vulnerabilities, Silencing the Self, and Stress}

The next segment of this chapter explores the significance, both theoretical and practical, of a possible association between silencing the self and stress. Although several authors have provided accounts that suggest that people high in self-silencing are exposed to elevated levels of stress, our survey of the literature revealed few empirical attempts to examine stress and self-silencing. The primary exception is a study of life stress and self-silencing in unipolar depression by Ali, Oatley, and Toner (2002). Stress and the contextual meaning 
of stress were assessed in this study via semistructured interviews. Ali and colleagues (2002) confirmed that there was an association between self-silencing and depression in this clinical sample, and they found higher levels of selfsilencing among women with relational stressors. Finally, an exploratory phase of this research showed that women with lower levels of self-silencing at the beginning of treatment showed greater reductions in depressive symptoms over time, relative to women with high levels of self-silencing prior to treatment.

Dependency, self-criticism, and perfectionism have all been linked consistently with stress, and there have been tests of the congruency hypothesis (i.e., achievement-based factors such as self-criticism and perfectionism will interact with the experience of achievement stressors to produce depression, while interpersonally based factors such as dependency will interact with the experience of interpersonal stressors to produce depression). Overall support for the congruency hypothesis has been mixed at best, but there is no doubt that there is a consistent association between these personality factors and stress.

The finding of an association between self-silencing and relational stress reported by Ali and colleagues (2002) fits nicely with past research in our laboratories on a particular form of stress. Specifically, we have focused on stress in the form of frequent negative social interactions. Negative social interactions have a substantial and negative impact on emotional reactions and thought processes, especially when the negative social interaction involves a conflict important with a significant other. Several researchers have reported a link between negative social interactions and reports of psychological distress (e.g., Bolger, DeLongis, Kessler, \& Schilling, 1989; Rook, 1984; Sandler \& Barrera, 1984). For instance, Bolger and colleagues (1989) had subjects complete diary accounts and provide mood ratings over a six-week period. Analyses established that interpersonal conflicts were the most upsetting stressors and these stressors accounted for over $80 \%$ of the variance in daily mood ratings.

Flett, Hewitt, Garshowitz, and Martin (1997) found in a sample of students that higher depression symptom scores were correlated significantly with the frequency of negative social interactions and with socially prescribed perfectionism, sociotropy, and autonomy. Additional results indicated that the frequency of negative social interactions accounted for unique variance in depressive symptoms over and above the variance predicted by personality traits, but it did not interact with these personality traits to predict unique variance in depressive symptoms. It was also found that the reported frequency of negative social interactions was correlated positively with socially prescribed perfectionism, sociotropy, and autonomy, especially among women.

Because self-silencing and interpersonal stress are seemingly associated, and frequent negative social interactions are linked with a perfectionistic 
orientation, we examined self-silencing, personality, and interpersonal stress by including the Inventory of Negative Social Interactions (INSI; Lakey, Tardiff, \& Drew, 1994) along with the other measures listed in Table 13.1. Lakey and colleagues (1994) developed the INSI to assess the frequency of negative social interactions. It can be seen in Table 13.1 that negative social interactions were associated with overall levels of self-silencing as well as elevated scores on all four STSS subscales.

We also included a measure of daily hassles that was created specifically by Kohn and his colleagues for use with university students (see Kohn, Lafreniere, \& Gurevich, 1990). This measure taps various factors that students may experience on a daily basis including a social mistreatment factor. Past research has established that daily life hassles represent a chronic and destructive form of stress that seems to have a greater negative impact on well-being than does the experience of major life events (see Blankstein \& Flett, 1992, for a discussion). In this instance, it can be seen in Table 13.1 that self-silencing was also associated with daily hassles.

These findings combine to suggest that people who have vulnerable personalities and who tend to engage in self-silencing are exposed to highly deleterious forms of stress. Daily interpersonal events that involve negative social interactions are bound to have a profound influence on these individuals, both in the short term in terms of distress and ruminating over upsetting events and in the long term in terms of exacting a significant toll through health consequences. There is growing evidence of the benefits of coping via emotional expression (Stanton et al., 2002), yet here we are describing individuals who have a tendency to be highly stressed and to react strongly to stress yet being unwilling or unable to express the stress, distress, and concerns to others. Clearly, these individuals should benefit greatly from stress counseling and other treatment interventions designed to encourage them to express themselves and seek out the support of other people.

\section{Personality and Self-Silencing in Women Versus Men}

The final segment of this chapter briefly considers the issue of whether the link between personality vulnerabilities and self-silencing is equally applicable to women and men. At present, systematic research on personality and self-silencing has not been conducted, so little is known about possible gender differences in the relevance and the associations that self-silencing have with personality constructs such as dependency, self-criticism, and perfectionism. Most existing research has been conducted with university student samples, and this reliance on student samples could possibly obscure gender differences; male university students may have more homogenous experiences than other people as a result of the common components of the student role and associated lifestyle. Thus, 
given the paucity of data, any observations here about gender differences are admittedly speculative.

This caution notwithstanding, it is important to highlight some key issues and provide suggestions for future research. Our new study on self-silencing in couples yielded little evidence of gender differences, so it is quite possible that there are more similarities between women and men than differences when it comes to the personality and self-silencing link. Nevertheless, it is quite possible that differences are expressed and experienced in different roles and interpersonal spheres (e.g., see Mauthner, Chapter 21).

\section{Conclusion}

Although Jack (1999a) has noted correctly that self-silencing is distinct from personality traits because self-silencing can fluctuate according to current relationship outcomes and issues, the current chapter indicates that self-silencing is linked clearly with dispositional personality traits associated with vulnerability to depression. Our review established that dependency, self-criticism, and various dimensions of perfectionism are all linked significantly with silencing the self. Moreover, there is some evidence indicating that self-silencing acts as a mediator or moderator in the association between personality and depression. One way of interpreting the mediational results is that self-silencing is one of the highly maladaptive responses of vulnerable individuals who are clearly very high in interpersonal sensitivity and responsiveness to negative interpersonal interactions and associated stressors. Although much of our analysis focused on self-silencing adults in interpersonal relationships, the association between self-silencing and personality vulnerability suggests that self-silencing is perhaps a long-lasting style that may be detectable among vulnerable children and adolescents. Regardless of whether this turns out to be true, as determined by future research, it is most certainly the case that there is the potential for great risk and distress among selfsilencing people who are also characterized by personality vulnerabilities. In general, our analysis highlights the need for continuing vigilance among clinicians, counselors, and educators and society as a whole because certain people are particularly vulnerable and they may seem to be functioning well even though they are suffering in silence.

Note

1. In this instance, we use the term "mediator" to refer to a variable $Z$ (i.e., silencing the self) that accounts for the effect of a predictor variable $X$ (i.e., trait personality vulnerabilities) on a criterion variable $Y$ (i.e., loneliness), and we use the term "moderator" to refer to a variable $\mathrm{Z}$ (i.e., silencing the self) that qualifies the effect of a predictor variable $\mathrm{X}$ (i.e., trait personality vulnerabilities) on a criterion variable $\mathrm{Y}$ (i.e., depression) (Baron \& Kenny, 1986). 


\section{References}

Ali, A., Oatley, K., \& Toner, B. B. (2002). Life stress, self-silencing, and domains of meaning in unipolar depression: An investigation of an outpatient sample of women. Journal of Social and Clinical Psychology, 21, 669-685.

Ali, A., Toner, B. B., Stuckless, N., Gallop, R., Diamant, N. E., Gould, M. I., et al. (2000). Emotional abuse, self-blame, and self-silencing in women with irritable bowel syndrome. Psychosomatic Medicine, 62, 76-82.

Andrews, B., Qian, M., \& Valentine, J. D. (2002). Predicting depressive symptoms with a new measure of shame: The Experience of Shame Scale. British Journal of Clinical Psychology, 41, 29-42.

Baron, R. M., \& Kenny, D. A. (1986). The moderator-mediator variable distinction in social psychological research: Conceptual, strategic and statistical considerations. Journal of Personality and Social Psychology, 51, 1173-1182.

Besser, A. (2004). Self- and best-friend assessments of personality vulnerability and defenses in the prediction of depression. Social Behavior and Personality, 32, 559-594.

Besser, A., Flett, G. L., \& Davis, R. A. (2003). Self-criticism, dependency, silencing the self, and loneliness: A test of a mediational model. Personality and Individual Differences, 35, 1735-1752.

Besser, A., Flett, G. L., \& Hewitt, P. L. (2004). Perfectionism, cognition, and affect in response to performance failure vs. success. Journal of Rational-Emotive and Cognitive-Behavior Therapy, 22, 301-328.

Besser, A., Flett, G. L., \& Hewitt, P. L. (2009a). Perfectionism and self-silencing in relationship adjustment and distress in couples. Manuscript in preparation.

Besser, A., Flett, G. L., \& Hewitt, P. L. (2009b). Perfectionistic self-presentation, selfsilencing, and distress in response to humiliation. Manuscript in preparation.

Besser, A., \& Priel, B. (2003a). A multisource approach to self-critical vulnerability to depression: The moderating role of attachment. Journal of Personality, 71, 515-556.

Besser, A., \& Priel, B. (2003b). Trait vulnerability and coping strategies in the transition to motherhood. Current Psychology, 22, 57-72.

Besser, A., \& Priel, B. (2005a). The apple does not fall far from the tree: Attachment styles and personality vulnerabilities to depression in three generations of women. Personality and Social Psychology Bulletin, 31, 1052-1073.

Besser, A., \& Priel, B. (2005b). Interpersonal relatedness and self-definition in late adulthood depression: Personality predispositions, and protective factors. Social Behavior and Personality, 33, 351-382.

Besser, A., Priel, B., Flett, G. L., \& Wiznitzer, A. (2007). Linear and nonlinear models of vulnerability to depression: Personality and postpartum depression in a high risk population. Individual Differences Research, 5, 1-29.

Blankstein, K. R., \& Flett, G. L. (1992). Specificity in the assessment of daily hassles: Life stress, locus of control, and adjustment in college students. Canadian Journal of Behavioural Science, 24, 382-398.

Blatt, S. J. (1974). Levels of object representation in anaclitic and introjective depression. The Psychoanalytic Study of the Child, 24, 107-157.

Blatt, S. J. (1990). Interpersonal relatedness and self-definition: Two personality configurations and their implications for psychopathology and psychotherapy. 
In J. L. Singer (Ed.), Repression and dissociation (pp. 299-335). Chicago: University of Chicago Press.

Blatt, S. J. (1995). The destructiveness of perfectionism: Implications for the treatment of depression. American Psychologist, 50, 1003-1020.

Blatt, S. J. (2004). Experiences of depression: Theoretical, clinical, and research perspectives. Washington, DC: American Psychological Association.

Blatt, S. J., \& Blass, R. (1996). Relatedness and self-definition: A dialectic model of personality development. In G. G. Noam \& K. W. Fischer (Eds.), Development and vulnerabilities in close relationships (pp. 309-338). Hillsdale, NJ: Erlbaum.

Blatt, S. J., Cornell, C. E., \& Eshkol, E. (1993). Personality style, differential vulnerability and clinical course in immunological and cardiovascular disease. Clinical Psychology Review, 13, 421-450.

Blatt, S. J., D’Afflitti, J. P., \& Quinlan, D. M. (1976). Experiences of depression in normal young adults. Journal of Abnormal Psychology, 85, 383-389.

Blatt, S. J., Quinlan, D. M., Chevron, E. S., McDonald, C., \& Zuroff, D. C. (1982). Dependency and self-criticism: Psychological dimensions of depression. Journal of Counseling and Clinical Psychology, 150, 113-124.

Blatt, S. J., Zohar, A. H., Quinlan, D. M., Zuroff, D. C., \& Mongrain, M. (1995). Subscales within the dependency factor of the Depressive Experiences Questionnaire. Journal of Personality Assessment, 64, 319-339.

Blatt, S. J., \& Zuroff, D. C. (1992). Interpersonal relatedness and self-definition: Two prototypes for depression. Clinical Psychology Review, 12, 527-562.

Bolger, N., DeLongis, A., Kessler, R. C., \& Schilling, E. A. (1989). Effects of daily stress on mood. Journal of Personality and Social Psychology, 57, 808-818.

Brown, G. W., Harris, T. O., \& Hepworth, C. (1995). Loss, humiliation, and entrapment among women developing depression: A patient and non-patient comparison. Psychological Medicine, 25, 7-21.

Cox, B. J., \& Enns, M. W. (2003). Relative stability of dimensions of perfectionism in depression. Canadian Journal of Behavioural Science, 35, 124-132.

Drew, S. S., Heesacker, M., Frost, H. M., \& Oelke, L. E. (2004). The role of relationship loss and self-loss in women's and men's dysphoria. Journal of Social and Personal Relationships, 21, 381-397.

Ellis, A. (2002). The role of irrational beliefs in perfectionism. In G. L. Flett \& P. L. Hewitt (Eds.), Perfectionism: Theory, research, and treatment (pp. 217-229). Washington, DC: American Psychological Association.

Farmer, A. E., \& McGuffin, P. (2003). Humiliation, loss and other types of life events and difficulties: A comparison of depressed subjects, healthy controls, and their siblings. Psychological Medicine, 33, 1169-1175.

Flett, G. L., Besser, A., \& Hewitt, P. L. (2005). Perfectionism, ego defense styles, and depression: A comparison of self-reports versus informant ratings. Journal of Personality, 73, 1355-1396.

Flett, G. L., Besser, A., \& Hewitt, P. L. (2009). Personality vulnerabilities, shame, and self-silencing in psychological distress. Manuscript in preparation.

Flett, G. L., Besser, A., Hewitt, P. L., \& Davis, R. A. (2007). Perfectionism, silencing the self, and depression. Personality and Individual Differences, 43, 1211-1222. 
Flett, G. L., Greene, A., \& Hewitt, P. L. (2004). Dimensions of perfectionism and anxiety sensitivity. Journal of Rational-Emotive and Cognitive-Behavior Therapy, 22, $39-57$.

Flett, G. L., \& Hewitt, P. L. (2002). Perfectionism: Theory, research, and treatment. Washington, DC: American Psychological Association.

Flett, G. L., Hewitt P. L., Blankstein K. R., \& Gray L. (1998). Psychological distress and the frequency of perfectionistic thinking. Journal of Personality and Social Psychology, 75, 1363-1381.

Flett, G. L., Hewitt, P. L., Endler, N. S., \& Bagby, R. M. (1995). Conceptualization and assessment of personality factors in depression. European Journal of Personality, 9 , 309-350.

Flett, G. L., Hewitt, P. L., Garshowitz, M., \& Martin, T. R. (1997). Personality, negative social interactions, and depressive symptoms. Canadian Journal of Behavioural Science, 29, 28-37.

Flett, G. L., Hewitt, P. L., Shapiro, B., \& Rayman, J. (2003). Perfectionism, beliefs, and adjustment in dating relationships. In N. J. Pallone (Ed.), Love, romance, sexual attraction: Research perspectives from current psychology (pp. 31-60). New Brunswick, NJ: Transaction Publishers.

Frost, R. O., \& DiBartolo, P. M. (2002). Perfectionism, anxiety, and obsessive-compulsive disorder. In G. L. Flett \& P. L. Hewitt (Eds.), Perfectionism: Theory, research, and treatment (pp. 341-371). Washington, DC: American Psychological Association Press.

Frost, R. O., Marten, P., Lahart, C., \& Rosenblate, R. (1990). The dimensions of perfectionism. Cognitive Therapy and Research, 14, 449-468.

Geller, J., Cockell, S. J., Hewitt, P. L., Goldner, E. M., \& Flett, G. L. (2000). Inhibited expression of negative emotions and interpersonal orientation in anorexia nervosa. International Journal of Eating Disorders, 28, 8-19.

Habke, A. M., Hewitt, P. L., \& Flett, G. L. (1999). Perfectionism and sexual satisfaction in intimate relationships. Journal of Psychopathology and Behavior Assessment, 21, 307-322.

Haring, M., Hewitt, P. L., \& Flett, G. L. (2003). Perfectionism, coping, and quality of intimate relationships. Journal of Marriage and the Family, 65, 143-158.

Harper, M. S., \& Welsh, D. P. (2007). Keeping quiet: Self-silencing and its association with relational and individual functioning among adolescent romantic couples. Journal of Social and Personal Relationships, 24, 99-116.

Hart, B. I., \& Thompson, J. M. (1996). Gender role characteristics and depressive symptomatology among adolescents. Journal of Early Adolescence, 16, 407-426.

Helgeson, V. S. (1994). Relation of agency and communion to well-being: Evidence and potential explanations. Psychological Bulletin, 116, 412-428.

Hewitt, P. L., \& Flett, G. L. (1991). Perfectionism in the self and social contexts: Conceptualization, assessment, and association with psychopathology. Journal of Personality and Social Psychology, 60, 456-470.

Hewitt, P. L., \& Flett, G. L. (2002). Perfectionism and stress in psychopathology. In G. L. Flett \& P. L. Hewitt (Eds.), Perfectionism: Theory, research, and treatment (pp. 255-284). Washington, DC: American Psychological Association Press.

Hewitt, P. L., \& Flett, G. L. (2004). Multidimensional Perfectionism Scale: Technical manual. Toronto: Multi-Health Systems Inc. 
Hewitt, P. L., \& Flett, G. L. (2007). When does conscientiousness become perfectionism? Current Psychiatry, 6, 49-60.

Hewitt, P. L., Flett, G. L., \& Ediger, E. (1995). Perfectionism, coping, and depression symptomatology in a clinical sample. International Journal of Eating Disorders, 18, 317-326.

Hewitt, P. L., Flett, G. L., Ediger, E., Norton, R., \& Flynn, C. (1998). Perfectionism chronic and state symptoms of depression. Canadian Journal of Behavioural Sciences, 30, 234-242.

Hewitt, P. L., Flett, G. L., Sherry, S. B., Habke, M., Parkin, M., Lam, R. W., et al. (2003). The interpersonal expression of perfection: Perfectionistic self-presentation and psychological distress. Journal of Personality and Social Psychology, 84, $1303-1325$.

Horney, K. (1950). Neurosis and human growth: The struggle toward self-realization. London: W.W. Norton \& Company.

Jack, D. C. (1991). Silencing the self. Cambridge, MA: Harvard University Press.

Jack, D. C. (1999a). Silencing the self: Inner dialogues and outer realities. In T. Joiner \& J. C. Coyne (Eds.), The interactional nature of depression (pp. 221-246). Washington, DC: American Psychological Association.

Jack, D. C. (1999b). Ways of listening to depressed women in qualitative research: Interview techniques and analyses. Canadian Psychology, 40, 91-101.

Jack, D. C. (2001). Understanding women's anger: A description of relational patterns. Health Care for Women International, 22, 385-400.

Jack, D. C., \& Dill, D. (1992). The Silencing the Self Scale: Schemas of intimacy associated with depression in women. Psychology of Women Quarterly, 16, 97-106.

Kohn, P. M., Lafreniere, K., \& Gurevich, M. (1990). The inventory of college students' recent life experiences: A decontaminated hassles scale for a special population. Journal of Behavioral Medicine, 13, 619-630.

Lakey, B., Tardiff, T. A., \& Drew, J. B. (1994). Negative social interactions: Assessment and relations to social support, cognition, and psychological distress. Journal of Social and Clinical Psychology, 13, 42-62.

Levy, K. N., Blatt, S. J., \& Shaver, P. R. (1998). Attachment styles and parental representations. Journal of Personality and Social Psychology, 74, 407-419.

Luthar, S. S., \& Blatt, S. J. (1993). Dependent and self-critical depressive experiences among inner-city adolescents. Journal of Personality, 61, 365-386.

Mongrain, M. (1998). Parental representations and support-seeking behaviors related to dependency and self-criticism. Journal of Personality, 66, 151-173.

Mongrain, M., \& Leather, F. (2006). Immature dependence and self-criticism predict the recurrence of major depression. Journal of Clinical Psychology, 62, 705-713.

Mongrain, M., Lubbers, R., \& Struthers, W. (2004). The power of love: Mediation of rejection in roommate relationships of dependents and self-critics. Personality and Social Psychology Bulletin, 30, 94-105.

Mongrain, M., \& Zuroff, D. C. (1994). Ambivalence over emotional expression and negative life events: Mediators of depressive symptoms in dependent and self-critical individuals. Personality and Individual Differences, 16, 447-458. 
Mongrain, M., \& Zuroff, D. C. (1995). Motivational and affective correlates of dependency and self-criticism. Personality and Individual Differences, 18, 347-354.

Nepon, T. B., Flett, G. L., Besser, A., \& Hewitt, P. L. (2009, June). Perfectionistic self-presentation and perfectionism cognitions in silencing the self. Poster presented at the annual meeting of the Canadian Psychological Association, Montreal, Quebec.

Nietzel, M. T., \& Harris, M. J. (1990). Relationship of dependency and achievement/ autonomy to depression. Clinical Psychology Review, 10, 279-297.

Nolen-Hoeksema, S., Wisco, B. E., \& Lyubomirsky, S. (2008). Rethinking rumination. Perspectives on Psychological Science, 3, 400-424.

Orth, U., Berking, M., \& Burkhardt, S. (2006). Self-conscious emotions and depression: Rumination explains why shame but not guilt is maladaptive. Personality and Social Psychology Bulletin, 32, 1608-1619.

Priel, B., \& Besser, A. (1999). Vulnerability to postpartum depressive symptomatology: Dependency, self-criticism and the moderating role of antenatal attachment. Journal of Social and Clinical Psychology, 18, 240-253.

Priel, B., \& Besser, A. (2000). Dependency and self-criticism among first-time mothers: The roles of global and specific support. Journal of Social and Clinical Psychology, $19,437-450$.

Radloff, L. (1977). The CES-D Scale: A self-report depression scale for research in the general population. Applied Psychological Measurement, 1, 385-401.

Rook, K. (1984). The negative side of social interaction: Impact on psychological wellbeing. Journal of Personality and Social Psychology, 46, 1097-1108.

Rude, S. S., \& Burnham, B. L. (1995). Connectedness and neediness: Factors of the DEQ and SAS Dependency scales. Cognitive Therapy and Research, 19, 323-340.

Sandler, I. N., \& Barrera, M., Jr. (1984). Toward a multidimensional approach to assessing the effects of social support. American Journal of Community Psychology, 12, 37-52.

Stanton, A. L., Danoff-Burg, S., Cameron, C. L., Bishop, M., Collins, C. A., Kirk, S. B., et al. (2002). Emotionally expressive coping predicts psychological and physical adjustment to breast cancer. Journal of Consulting and Clinical Psychology, 65, 875-882.

Stephens, B. J. (1987). Cheap thrills and humble pie: The adolescence of female suicide attempters. Suicide and Life-Threatening Behavior, 17, 107-118.

Tangney, J. P., Niedenthal, P. M., Covert, M. V., \& Barlow, D. H. (1998). Are shame and guilt related to distinct self-discrepancies? A test of Higgins' (1987) hypotheses. Journal of Personality and Social Psychology, 75, 256-268.

Tangney, J. P., Wagner, P. E., \& Gramzow, R. (1989). The test of self-conscious affect. Fairfax, VA: George Mason University.

Thompson, J. M. (1995). Silencing the self: Depressive symptomatology and close relationships. Psychology of Women Quarterly, 19, 337-353.

Thompson, J. M., Whiffen, V. E., \& Aube, J. A. (2001). Does self-silencing link perceptions of care from parents and partners with depressive symptoms? Journal of Social and Personal Relationships, 18, 503-516.

Whiffen, V. (2007). A secret sadness: The hidden relationship patterns that make women depressed. Oakland, CA: New Harbinger Publications. 
312 SILENCING THE SELF ACROSS CULTURES

Whiffen, V., \& Aube, J. (1999). Personality, interpersonal context, and depression in couples. Journal of Social and Personal Relationships, 16, 369-383.

Wiseman, H. (1997). Interpersonal relatedness and self-definition to the experience of loneliness during the transition to university. Personal Relationships, 4, 285-298.

Zuroff, D. C., \& Fitzpatrick, D. (1995). Depressive personality styles: Implications for adult attachment. Personality and Individual Differences, 18, 253-365. 


\section{QUERIES TO BE ANSWERED BY AUTHOR (SEE MANUAL MARKS)}

IMPORTANT NOTE: Please mark your corrections and answers to these queries directly onto the proof at the relevant place. Do NOT mark your corrections on this query sheet.

Chapter 13

\begin{tabular}{lcl}
\hline Q. No. & Pg No. & \multicolumn{1}{c}{ Query } \\
\hline AQ1 & 287 & $\begin{array}{l}\text { We have shortened the Running head please check is this } \\
\text { ok? }\end{array}$ \\
\hline
\end{tabular}

